\title{
ACTION LEARNING QUESTIONS: MAKING SENSE OF ORGANIZATIONAL CHAOS
}

\author{
(CASE STUDY)
}

\author{
Richard Hale \\ Bristol, England, UK \\ Jennifer Bowerman \\ Edmonton, AB, Canada
}

\begin{abstract}
This article uses a dialogic and questioning approach between the two authors, to explore how action learning questioning as a process has been used to create transformation and capability in some organizations impacted by massive change. Action Learning, based on the original work of Reg Revans, is a question driven approach enabling complex business issues to be explored through action and reflection with fellow set members. The authors narrate how such an approach has been used as the foundation for programs of professional development qualifications, with the assistance of some universities willing to forego their usual practice of teaching and testing concepts and theories, acknowledging that these new business development programs can succeed in bringing about results, resilience and competence in workforces battered by change fatigue and chaos. Too often organizational development concepts have become dry theoretical concepts in text books. This exchange demonstrates how they can come to life through questioning, reflective action and organizational support using evidence from major programs now underway in government and commercial sectors in the UK. The authors demonstrate how Action Learning Questioning based initiatives have the capacity to build social capital, and generate effective learning in complex and rapidly changing business and organizational environments. It concludes with suggestions for the future.
\end{abstract}

Keywords: Action Learning, Organization Development, The Learning Organization, Chaordic Organizations.

DOI: http://dx.doi.org/10.15549/jeecar.v3i2.143

\section{INTRODUCTION}

Organizations today, whether private or public, are messy. Battered by the speed of change, needing to be constantly innovative, and responsive, traditional bureaucracies with their "distinct ethos, slow, inefficient and impersonal" (Osborne and Graebler p. 14), have been swept away. New rules, austerity, privatization, technology, globalization, different skills, changing hierarchies, the nature of knowledge itself, different relationships, changing demographics, all 
these factors and many more, have impacted work, how we do it, and what we can expect from our efforts, whether we work for a business or a service organization within a bureaucracy. Management theories may be useful to know, but without support in terms of their implementation, they often fail in terms of necessarily delivering the business and organizational results we wish to see.

In many respects we may call today's organizations chaordic - where the familiarity of order has been displaced by disorder, compelling us to recognize that 'business as usual' no longer works as an organizational practice or intention. Managing change from the top often does not recognize the experience and learning that employees carry in their heads. When the former machine model of Frederick Taylor meets the complexity of disequilibrium (Prirogine and Stengers, 1984), it leads to organizational and business problems that are difficult to resolve without the involvement of those who are actually caught up in the change process itself at the line level. Having to constantly adapt to a changing environment without the clear certainty of even what the change is, is difficult to say the least, and can result in serious fatigue and dysfunction.

This paper is about the authors' management experiences drawing on an approach to organisation and professional development called action learning. This is based on the life-long work of Reg Revans, and in particular the focus on insightful questioning, where groups of 5-8 persons, known as an action learning set, address complex business and organizational issues, and then take informed action from which they continue to learn. Both authors are highly skilled action learning practitioners, achieving doctorates using the practice, albeit one has spent many years teaching previously published material and theory in traditional teaching forums such as universities, whilst the other has pursued the practice of action learning in commerical, public and third sector organisations.

The methodology of this paper is in itself action based in that its core is an interview between the two authors as reflective practitioners demonstrating both the theory of action in terms of their respective experience and the learning that has accrued. Furthermore the dialogue and shared reflection of our own experience has created a new level, or cycle of understanding which it is hoped will be enhanced further through wider sharing with professional and academic communities, including via this paper and its presentation at the International Business and Management Conference, University of Economics, Prague, November 11, 12, 2016.

Thus the paper demonstrates the following:

1) It documents via an interview format between the two practitioners authors, what can be achieved through action learning as a practice in an organization and thus serves to demonstrate some of the successes and some pitfalls. Action learning is in itself a questioning process. This paper uses questioning where one author asks questions of the other, as a means of explaining through narrative and reflection how action learning has been transformative for some organizations.

2) It summarizes a formal Action Learning Question process which can work in an organization to both effect change and build the competence and learning of organizational managers, leaders, professionals and employees simultaneously. Included is information from a recent action learning initiative which has some significant results in terms of building capacity for change.

3) It demonstrates how traditional programmed knowledge from the field of organizational behaviour and organizational development can be transformed into action based behaviour and learning.

4) Finally the authors offer some concluding thoughts on the value of such initiatives and consider 'Where to next?' including some proposals grading the role of academic teaching and research in the field of organisation development, change and behaviour.

\section{CRITICAL QUESTIONS AND RESPONSES FROM ONE PRACTITIONER TO ANOTHER}

Jennifer Bowerman (JB) asks her colleague Richard Hale (RH) to tell us about his experience with Action Learning

RH: When Jennifer and I first met, in the UK, we were both completing our action learning based 
doctorates with a professional organization supported by a university. The organization was dedicated to building the professional development of business leaders through access to qualifications using action learning. My doctorate, under the supervision of Dr. Alan Mumford who co-authored the Honey and Mumford learning style preferences questionnaire, was about how coaching and mentoring supported learning for individuals and businesses. Shortly after my graduation I was invited to address two challenges, one from a large banking group in the UK, and the other from the action learning professional institute. The bank wished to run a senior leadership development program which focused around real organizational challenges but which would not take its executives away from the business for too long and which delivered impact for the business. The professional institute wanted me to look at their qualifications, and the extent to which they were genuinely using the principles of action learning in their design.

As a result of these two experiences, I ended up helping to develop the Action Learning Question process which enabled us to offer a route to the first fully organisation based Action Learning based Master's degree in leadership for a finance business in the UK. Managers on the program would negotiate real organizational and business challenges and articulate these in the form of a question. The question would be agreed with key stakeholders in the business and approved by their academic supervisor and would inform a process of investigation, work with the action learning set (5-8 people), and the necessity to take informed action. Also they would summarize their learning in the form of a written paper or report which would be assessed and accrue credit at a Masters level.

JB: What sorts of questions did the participants actually address?

RH: Action Learning Questions have to be based around real organizational issues. Action Learning is business driven. So in the bank at the time they faced significant challenges around impairments or bad debts, staff engagement, and some key strategic decisions around whether to maintain a branch structure. These sorts of issues became the basis for the action learning work of participants. By addressing these intractable and complex multi-faceted problems, participants would support each other in working out how to proceed. These were the kinds of questions which the most senior people in the business knew would present a challenge for the future, but they realized they could not be tackled by simply turning them into a project plan. There were too many unknowns and options to the extent that even those leaders at the very top did not know what to do next.

JB: This is clearly a very business relevant approach. How do you gain commitment from the very top of the business? Don't those at the top fear a loss of control? Certainly this has been my experience whereby those top managers seemed to fear these kinds of initiatives, and while they understood formal university programs (which Revans would have called P, as in Programed Knowledge), and actually partook of them, the possibility of using action learning as a business development program within the organization seemed to pass them by. How have you managed to get around this kind of reaction which speaks to a need for control, power, and politics and a fear of letting go?

RH: Sure you need commitment from the very top to embark on such a program which is about developing the organization rather than simply running a training program. I was fortunate in that the first two clients I worked with did show a commitment from the very top. We actually formed a steering group with the Managing Director as the Chair and the HR Director, various learning and development professionals and other directors and eventually participants as members. It may take time to form such a group, because this type of program does require a good ally inside the business. We also trained line managers of participants to become effective mentors and supporters of the program to ensure they did not feel marginalized. But it always was a learning process.

JB: How does a university fit into such a program? What has been your experience?

RH: Universities that accredit this kind of program also have to realize that they are breaking new ground. First they have to recognize that they are not accrediting knowledge based content which is the $\mathrm{P}$ or programed knowledge in the famous Revans equation - Learning $(\mathrm{L})=$ Programmed Knowledge (P) + Questions (Q). Universities and business schools are very familiar 
with managing, working with, teaching, publishing and claiming programmed knowledge. However they are less familiar with accrediting the process of rigorous learning at a Masters level where the nature of the knowledge being gained is different for all participants and determined by a question about the business and determined by the business rather than by the faculty of business school. Fortunately there are a few business schools and universities that have developed an effective process and systems for helping people who are working to capture and put forward their work based learning for accreditation.

This does however require a very client centred approach. Within such a programme, the role of the university or business school is to ensure that rigorous standards are maintained in terms of the level of work which is presented and assessed. What is being assessed is not so much the acquisition of content based technical knowledge, but the capability of managers to work at a particular level intellectually in terms of their ability to define problems, to manage their own learning and to apply analytical skills as they proceed with action in a change environment. Given the accelerating rate of change, I believe that this approach to accreditation will become increasingly important in the future. I have been fortunate to find various accreditation partners within the traditional world of the university, over the past fifteen years who have had the vision to recognize that the academic and intellectual rigour lies in the ALQ process rather than in the requirement to produce huge knowledge-based program designs.

JB: Tell us more Richard, about where else you have been able to apply the ALQ process to leadership and development?

RH: It has been used to support continuing professional development (CPD) in the field of business accountancy. Rather than accountants accruing their CPD credits by simply counting the hours spent at external workshops, they tackle Action Learning Questions around important business challenges in their field over a period of four months. We have also applied this to some emerging professional fields in the context of global outsourcing. It has also been used in not for profit organizations to help them address challenges around governance and strategic changes necessary because of changing external environments as in Australia. Importantly, over the last two years it has been applied to the UK Civil Service as part of an organization development capability program. Working hand in glove with a company of Organization Development specialists - Mayvin, we have been able to develop an accreditation program where Human Resource and Organization Development specialists have been able to confront the changes they are experiencing by learning, or in some cases, re-learning the OD theories and concepts, but bringing them alive as they selectively use them to expand their practice through action and reflection. Again like the masters programme in the bank, here they tackle thorny business related challenges using a Questions driven approach. They work at postgraduate level, but not in order to learn theory for the sake of it - they are concerned with improving their own professional capabilities and practice and at the same time improving their business.

JB: This is of course where I have come into the picture, because I have been introduced to the program as a result of my role as a second assessor for some of the written papers that have been completed. I worked in the public service myself in Canada and many of the issues raised by the participants were incredibly familiar to my own work experience and indeed reflected issues raised by my own doctoral work. I want you to tell us more about the program and why you believe it is so important? How in your opinion does it build social capital and hence a learning organization which is of interest to both of us?

\section{RH:}

Right now it is an ongoing program, with more than 200 civil servants mainly from Human Resource business partner type roles so far, who have completed an Action Learning Question (we call it an Organisation Development Question in this case) focused on a real organizational challenge. As a result of leading the Action Learning component of the program, I recently worked on an action impact review drawn from around a million words written by participants about the nature of the questions and challenges that they had addressed through their work on the programme. This is large scale. The program has spanned across a number of ministries, departments and agencies of the Civil Service. 
There are many examples of learning documented that have clearly had a significant impact on the participants, including the manner in which they approach their internal clients, the methods they use to develop client relationships, and the techniques that they apply in working with teams within the business. There is much more to be written about this program, but it is apparent even at this point that there are significant benefits to running a program on this scale over time. There is indeed clear evidence of the development of social capital across the service. We are seeing impact on the internal civil service in terms of the participants, but also some cases impact on the service being delivered to their external clients, often the public citizens.

Social capital is developed as a considerable number of people have acquired some common knowledge of the tools, methods and ways of thinking around organizational development. But perhaps this is only a part of the story. Significant social capital has been created by the formation of both formal and informal networks which span across different departments and different levels. Participants have been required through completion of their ALQ OD projects to engage with key stakeholders within the business. We are now investigating the extent to which there has been a knock-on effect in terms of learning being transferred to such stakeholders.

After 15 years of this kind of work, I can now state that we are close to supporting the development of a learning organization. This is not easy because in some early experience with other organizations, I found that just as we were gaining organizational momentum, a significant reorganization would take place, and often the program which was having such an impact was associated with the old regime, and quite often the baby was thrown out with the bathwater! This relates to another challenge really - how to sustain learning across organizations over time.

JB: My own real observation within the papers I have read and assessed was the extent to which so many of the participants were able to bring organizational theory to life. Teaching the theory without a need to address organizational or business issues always, at least for me, seems to have limited value. This program allowed people to learn about a significant organizational and self-development theory and then actually choose to use the most appropriate components to achieve their business goals and solve problems on the ground. The presence of Action Learning Sets and the written ALQ components served to build ongoing reflection and assessment in terms of their overall value. So for me, actually reading these papers was a very powerful learning experience. As a final conclusion, would you care to comment on how theory and practice come together as we make our way through what can often seem like chaotic organizations?

RH:

It is important to note that we are working with practitioner leaders and managers who are faced first and foremost with significant organizational challenges. These might relate to real financial, project, team, or people issues. We should not start by teaching managers the topics of HR, finance, or team management as discrete subjects. We start by helping them to articulate their real problems as questions. Once they have done this, they can use a process we call Knowledge Mapping to work out what theory might be relevant for them to research, or what models or tools are appropriate for them to apply. We also bring to the fore something not often talked about at business school. This relates to the power, political, values, and cultural issues which are often left suppressed underground. The process of knowledge mapping assists in helping people define what they know, what they believe might be true 'underground', and what they believe could be true as they search the 'sky'. Recognizing the sensitivities of how people really feel in organizations helps to bring them to the surface in a constructive way, and allows the types of theory you have mentioned, to be applied to live issues.

\section{WHERETO FROM HERE - THOUGHTS GOING FORWARD? SOME JOINT OBSERVATIONS}

Clearly the problems facing organizations are not going to become any easier. Consideration of global trade agreements which have to be implemented, the implications of referenda such as the recent Brexit vote in the UK, the global displacement of people, global health issues such as Ebola, climate change, political turmoil - all of these and many more, mean that the services and organizations we have always taken for granted, 
are hugely challenged. Our current reality is that change is happening at an unprecedented rate. It has been suggested that change will soon be occurring at 10 times the speed and 300 times the scope of the Industrial Revolution. Yet the first principles of Action Learning were derived by Reg Revans from the context of change back in the 1930s, almost 90 years ago and are as relevant now as they were then. Revans developed his concepts and practice out of his original work as a research scientist at the Cavendish Laboratories in Cambridge, under the famous Ernest Rutherford, recognizing that his fellow scientists, many of whom were Nobel prize winners, were facing challenges in atomic physics that had never been faced before. There was no book or authority to provide answers. Having the wisdom to recognize that they needed to 'trade in their ignorance', these scientists became incisive questioners and learners. As they asked insightful questions of each other, they found a route forward through collaboration, working as 'comrades in adversity'. This is our reality today.

Both authors of in this paper recognize that unless people are engaged in the thinking and decision making about the work they do, they will have low commitment to new ways of working imposed from above or from the centre. They will become cynical as they recognize that their own insights are ignored. Overall 'change competency' is low, and even with external training and development programs, often underfunded, the results all too often leave much to be desired. Action learning as a process in organizations, addressing real organizational and business issues, can only build competence. It can shift patterns, and build behavioural change, as the results of these programs described above demonstrate.

We recognize that the call for action learning programs to be implemented and documented can only help to build a necessary momentum. The programs referenced in this paper are building professional qualifications through the Action Learning Questions process described above and they have a major contribution to make for all workforces internationally which are racked by tumultuous changes never envisaged before.

This paper merely represents a taste of what is possible when organizations can make the space for people to acknowledge what they do not know, hold back from prescribing solutions, and allow those involved in change on the battle lines, to lead the way.

\section{POSTSCRIPT - THE ROLE OF ACADEMIA AND BUSINESS SCHOOLS}

Finally, some thoughts on the role of international universities and business schools in making a positive contribution to this agenda. The first draft of this paper was prepared as an Organizational Development Paper for presentation at International Business and Management Conference, University of Economics, Prague, November 11, 12, 2016 in the stream called Organisation Development. This was at a time globally when we were experiencing a sense of not knowing, of fear of uncertainty based on major world events such as the USA election of Donald Trump, the Brexit referendum result in the UK, and ongoing threats to international security accompanied by a continuing refugee crisis. These compelling macro issues featured highly in the presentations given by other speakers, notably Thomas Hanson a former USA diplomat and the renowned Professor Henry Mintzberg, writer around strategy, leadership and organisations. Perhaps it was a mark of these figures that they were willing to stand as such 'experts' in front of conference and admit they did not have the answers. It brought to mind the point made by Reg Revans that when in a state of ignorance we need to acknowledge this and work with our ignorance by developing appropriate questions that support collaborative thinking, learning and action.

It was also noticeable to the authors that at this conference several international university and business school scholars presented their work in the field of organisation development. Presentations included for instance studies of the challenges of establishing Small and Medium Size Enterprises (SMEs) in Russia, the motivation of demotivated business school students in an undergraduate programme, a study of the sales process in the Polish housing industry and the development of a proposed model for conceptualising the capacities and capabilities of organisations in the knowledge economy.

Perhaps not surprisingly as this was an academically oriented conference, the dominant methodological paradigm of the research reported was from a scientific, positivist ontological orientation. Within such a paradigm, researchers 
tend to lean towards methodological approaches that include literature reviews, survey analysis and quantitative data processing. In these cases, researchers and/or their institutions had separated quite clearly theory from practice. They were more concerned with theory than practice. When the presenters sought ideas on what might be the next stage of their research the suggestion that the authors of this paper made was that they might move into action. We suggested they could engage with the organisations they were researching, involving them as active and interested coresearchers seeking to understand and address the problems they face on the ground. Such an approach would mean embracing action research methods and recognising the value of collaborative action learning. Professor Henry Mintzberg in his book 'Managers Not MBAs' provides an excellent critique of the way in which the dominant method of teaching management and leadership to future organisation leaders, the Harvard Case Method, has failed to impact business and society positively. This was written somewhat prophetically just before the 2008 global financial crisis. To paraphrase and update the observation of Reg Revans - action learning is so simple a concept it has taken universities some 80 years to fully misunderstand it. And back to Mintzberg who now implores us to rebalance society, perhaps the question we should consider is how can we break down the barriers between those sectors representing public, private and plural, or commercial, government and education sectors and work collaboratively to effect action and change across all three?

\section{REFERENCES}

Argyris, C. (1990), Overcoming Organizational Defenses, Allyn \& Bacon, Boston, MA.

Bowerman, J. and Peters, J. (1999), "Design and evaluation of an action learning program-a bilateral view", The Journal of Workplace Learning: Employee Counselling Today, Vol. 11 Issues 3 and 4, pp. 131-140.

Bowerman, J. (2003), "Leadership development through action learning: an executive monograph", Leadership in Health Services, Vol. 16 Issue 4, pp. 6 - 14.

Cheung-Judge, Mee-Yan and Holbeche, Linda, (2015), Organizational Development: A
Practitioner's Guide for $O D$ and $H R, 2^{\text {nd }}$ ed.

Kogan-Page, London.

Collingham, B., Critten, P., Garnett, J. and Hale, R. (2007), A Partnership Approach to

Developing and Accrediting Work Based Learning - Creating Successful Work Based Learning - Meeting the Skills Challenge for

Performance Improvement, Inaugural Conference, British Institute for Learning and Development, Royal Society of Medicine, London 17 May 2007.

Garvin, D.A. (1993), “Building a learning organization”, Harvard Business Review, JulyAugust, pp.79-91.

Hale, R., (2014), “Knowledge mapping as a research method in a methodological context", Unpublished monograph.

Hale, R. (2014), "Fundamentals of action learning”, Training Journal, August, pp. 30-36.

Hale, R. (2014), “Fundamentals of action learning: Knowledge mapping”, Training Journal, September, pp. 15-17.

Hale, R.I. and Saville, M. (2014), "Nurturing the H in HR: using action learning to build organisation development capability in the UK Civil Service", Action Learning: Research \& Practice, October, pp. 1-19.

Kolb, D. (1984), Experiential Learning. Prentice Hall, New Jersey, Englewood Cliffs.

McDevitt, U. (2006), Action Learning - The CPD Approach, Accountancy Ireland, August, Vol. 38 , No. 4

Mintzberg, Henry, (2004), Managers Not MBAs: A Hard Look at the Soft Practice of Managing and Management Development, BerrettKoehler Inc. San Francisco.

Mintzberg, Henry, (2015), Rebalancing Society: Radical Renewal, Beyond Left, Right, and Center, Berrett-Koehler Inc. San Francisco.

Osborne, D.and Gaebler, T. (1992), Reinventing Government: How the Entrepreneurial Spirit is Reinventing Government, Madison-Wesley, Reading, Mass.

Prigogine, I. and Stengers, I. (1984), Order out of Chaos: Man's New Dialogue with Nature, Bantam Books, New York.

Pedlar, M. (Ed.) (1991), Action Learning in Practice, $2^{\text {nd }}$ ed. Gower, Aldershot. 
Revans, R.W. (1982), The Origins and Growth of Action Learning, Chartwell-Bratt, London, Bromley.

Revans, R.W. (1983), “Action learning- its terms and character", Management Decision, Vol.21, No. 1.

Revans, R.W. (1983), “Action learning-the skills of diagnosis", Management Decision, Vol. 21, No.2.

Revans, R.W. (1998), ABC of Action Learning: Empowering Managers to Act and to Learn from Action, Lemos and Crane, UK.

Wills, G. (1993), Your Enterprise School of Management, MCB University Press, Bradford.
ABOUT THE AUTHORS

Richard Hale email: Richard@al-int.com

Dr. Richard Hale is founder of Action Learning International (www.al-int.com), a research and academic consultancy working internationally in the field of organization, leadership and professional development. He is based in the UK and works extensively internationally including in Australia, Africa, and Europe in government, commercial, not for profit and educational sectors. His experience in UK corporations in corporate HR and Learning and Development and his doctoral research in coaching and mentoring have been influential in his development of a work based learning approach to the use of accredited action learning where insightful questions form the basis for collaborative learning. This has been applied to Master's level for leadership development in international banks, construction firms and over the past three years in the UK Civil Service to build organization development capacity as the public service faces major transformation. Richard has published several books and articles on behavioural aspects of leadership and organizational development and the Action Learning Process.

Dr. Jennifer Bowerman is from England where she obtained her BSc in sociology, then a Master's from the University of Saskatchewan, and later, after many years in government working in organizations specializing in human rights and safety services. She obtained a Doctorate in Management from Southern Cross University specializing in Action Learning. After teaching in traditional undergraduate and graduate classes subjects such as organizational culture, leadership and learning, and organizational behavior, in Switzerland and Edmonton, Alberta, she is now working with former doctoral colleague Dr. Richard Hale assisting with a major action learning organizational change project impacting an entire government service as it faces monumental change. Jennifer has published a number of professional articles, and is Editor of Leadership in Health Services, as well as on the Editorial Review Board of the Journal of Business and Retail Management Research. 